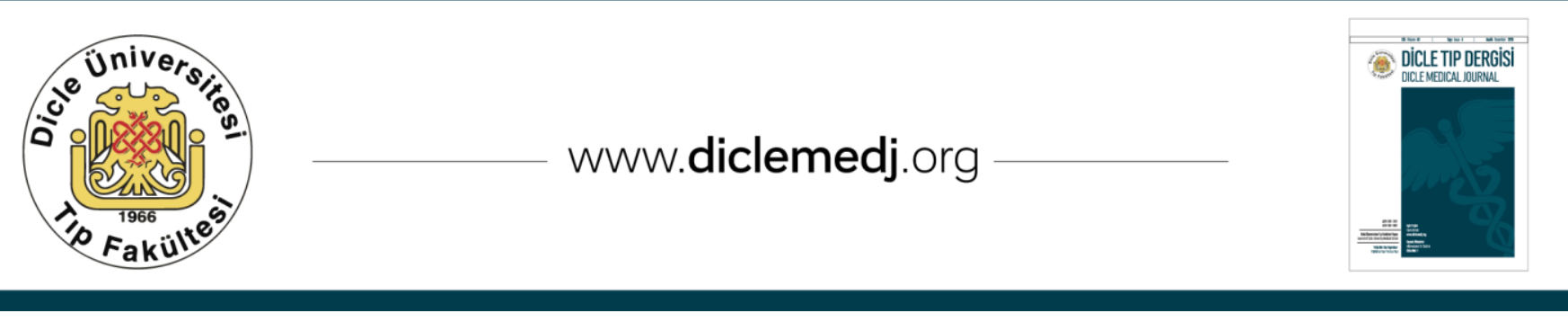

Olgu Sunumu / Case Report

\title{
Sol Pnömotoraks ile Santral Kitle Pnömonektomi Sonrası Kontralateral Pnömotoraks
}

\author{
Onur Derdiyok ${ }^{1}$, Cağatay Saim Tezel2 ${ }^{2}$,ilker Kolbaş ${ }^{3}$, Serda Metin Kanbur ${ }^{4}$, \\ Levent Alpay5, İrfan Yalçınkaya ${ }^{6}$
}

${ }^{1}$ Sağlık Bilimleri Üniv. Süreyyapaşa Göğüs Hastalıkları ve Göğüs Cerrahisi Eğitim ve Araș. Hastanesi İstanbul, Türkiye ORCID: 0000-0001-9994-8501 ${ }^{2}$ Sağllk Bilimleri Üniv. Süreyyapaşa Gögüs Hastalıkları ve Göğüs Cerrahisi Eğitim ve Araş. Hastanesi İstanbul, Türkiye ORCID: 0000-0001-5272-6215

${ }^{3}$ Sağllk Bilimleri Üniv. Süreyyapaşa Göğüs Hastalıkları ve Göğüs Cerrahisi Eğitim ve Araș. Hastanesi İstanbul, Türkiye ORCID: 0000-0003-1656-9595

${ }^{4}$ Sağllk Bilimleri Üniv. Süreyyapaşa Gögüs Hastalıkları ve Gögüs Cerrahisi Eğitim ve Araş. Hastanesi İstanbul, Türkiye ORCID: 0000-0003-3983-9420

${ }^{5}$ Sağllk Bilimleri Üniv. Süreyyapaşa Göğüs Hastalıkları ve Göğüs Cerrahisi Eğitim ve Araș. Hastanesi İstanbul, Türkiye ORCID: 0000-0001-8872-166X

${ }^{6}$ Sağllk Bilimleri Üniv. Süreyyapaşa Gögüs Hastalıkları ve Göğüs Cerrahisi Eğitim ve Araș. Hastanesi İstanbul, Türkiye ORCID: 0000-0002-5841-4080

Geliş: 15.01.2017, Revizyon: 07.09.2017, Kabul Tarihi: 05.10.2017

Özet

Pnömonektomi sonrası pnömotoraks gelişmesi morbidite ve mortalitesi yüksek bir durum olup ender seyreder. Sol ana bronșta kitlesi bulunan olgumuzda fiberoptik bronkoskopi (FOB) sonrası iyatrojenik pnömotoraks gelişti, vitalleri stabil olduğu için tüp torakostomi uygulanmadı. Aynı seansta mediastinoskopi ve pnömonektomi uygulandı. Bu çalışmada, postoperatif erken dönemde kontralateral pnömotoraks gelişen olgu literatür eşliğinde sunulmaktadır.

Anahtar kelimeler: Kontralateral pnömotoraks, pnömonektomi, iyatrojenik pnömotoraks.

\section{Contralateral Pneumothorax After Central Mass Pneumonectomy with Left Pneumothorax}

\section{Abstract}

The development of pneumothorax after pneumonectomy is a rare condition which has high morbidity and mortality. In our case with left main bronchus mass iatrogenic pneumothorax developed after fiberoptic bronchoscopy (FOB), tubal thoracostomy wasn't performed because the patient's vitals were stable. Mediastinoscopy and pneumonectomy was performed in the same session. In this study, a case of contralateral pneumothorax developed in the early postoperative period is presented with literature.

Keywords: Contralateral pneumothorax, pneumothorax, iatrogenic pneumothorax.

DOI: $10.5798 /$ dicletip.362493

Yazışma Adresi / Correspondence: Onur Derdiyok, Süreyyapaşa hastanesi göğüs cerrahisi Maltepe İstanbul, Türkiye e-mail: onur_derdiyok@hotmail.com 


\section{GİRIS}

Cerrahi ve anestezideki gelişmelere rağmen pnömonektomiden sonra gelişen komplikasyon oranı, oldukça yüksektir. Çeşitli yayınlarda bu oranın \%11 ile 50 arasında değiştiği belirtilmektedir. Komplikasyonların çoğu fatal olmayıp, oluşmadan önlenebilmektedir. Pnömotoraks nadir olmakla beraber en sık gözlenen komplikasyon aritmidir. Pnömotoraks meydana gelmesi kritik bir durum olup morbidite ve mortalitesi yüksek seyreder. Bu çalışmada, hemoptizi nedeniyle takip edilen, sol ana bronşta kitlesi tespit edilen hastaya aynı seans mediastinoskopi ve sol pnömonektomi uygulandı. Mediastinoskopi ile 2L 4L ve 7 LAP örneklendi. Preoperatif sol santral kateter uygulanan ve mediastinoskopi sonrası desatüre olmayan postoperatif erken dönemde kontralateral pnömotoraks gelişen olgu sunulmaktadır.

\section{OLGU}

Atmış dokuz yaşında erkek hasta hemoptizi ve nefes darlığı şikâyetleri ile kliniğimize başvurdu. Posterior anterior (PA) grafide sol hiler bölgede dansitide artışı görüldü (Şekil 1). Bronkoskopide sol ana bronş lateral duvarından kaynaklanan, distaline geçilemeyen, frajilkitle tespit edildi. Kontrol grafisinde pnömotoraks saptanmış olmasına rağmen, vitalleri stabil olan hastaya tüp torakostomi düşünülmedi. Oksijen tedavisi ile takip edildi. Çekilen bilgisayarlı tomografide (BT) sol üst lobda $4 \times 6 \mathrm{~cm}$ kitle, apikal bölgede minimal pnömotoraks vemaksimumçapı $10 \mathrm{~mm}$ olan plevral efüzyon saptandı (Şekil 2). PET CT'de sol ana bronş distalini obstrükte eden sol akciğerde total atelektaziye neden olan malignite ile uyumlu 3,5x4 cm kitle (SUDmax: 17,3) tespit edildi (Şekil3). FOB ile alınan örnekleme sonucu patoloji skuamöz hücreli akciğer karsinomu olarak tanımland. Ultrasonografi (USG) eşliğinde alınan plevral sıvıdan malignite tespit edilmedi. Bronkoskopi öncesi solunum fonksiyon testleri normal sinırdaydı (FEV1: 2,11lt \%61).

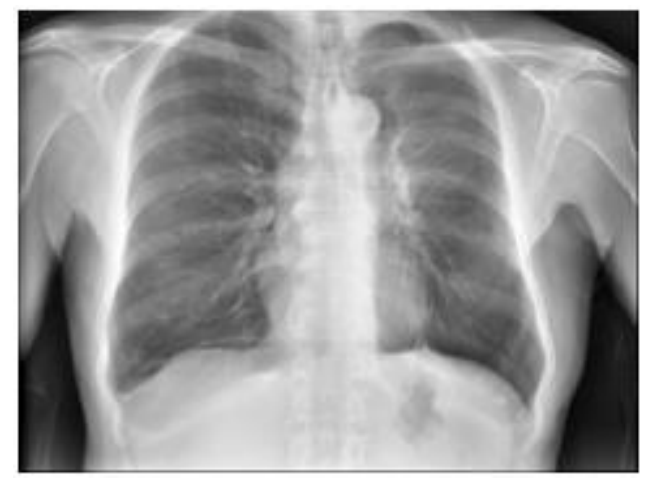

Şekil 1. Preoperatif posterioranterior akciğer grafisinde sol hiler bölgede dansite artışı görülmektedir

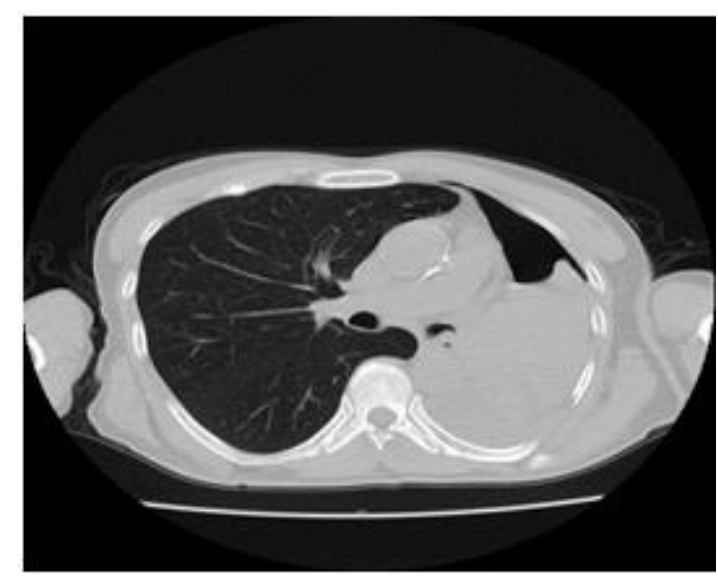

Şekil 2. Fiberoptik bronkoskopi sonrası çekilen toraks bilgisayarlı tomografisinde sol üst lobda $4 \times 6 \mathrm{~cm}$ kitle, apikal bölgede minimal pnömotoraks ve maksimum çapı $10 \mathrm{~mm}$ olan plevral efüzyon

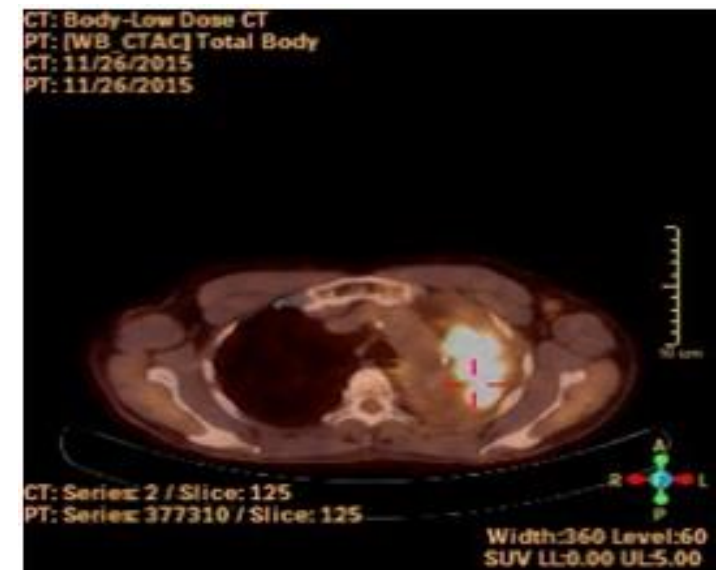

Şekil 3. PET CT'de sol ana bronş distalini obstrükte eden sol akciğerde total atelektaziye neden olan malignite ile uyumlu 3,5x4 cm kitle (SUDmax: 17,3) görülmektedir 
Akciğer kanseri ve mediastinal lenfadenopati tanısı nedeniyle öncelikle mediastinoskopi ve lenf bezi (2L-4L-7) örneklendi. Preoperatif lenf nodu reaktif kalması üzerine torakotomi ile sol pnömonektomi yapıldı. Olgu, patolojik olarak T3N0M0 Evre IIB evrelendi. Postoperatif erken dönemde nefes darlığı ve saturasyonun \%40 seviyesine kadar düşmesi nedeniyle entübe edildi. Kontrol anterior posterior (AP) akciğer grafisinde sağda pnömotoraks saptanması üzerine (Şekil4) acil tüp torakostomi uygulandı. AP grafi kan gazı ve solunumsal parametreler düzelmesi üzerine ekstübasyon yapıldı. Hasta postoperatif 1 . gün sağ tüp torakostomi, postoperatif 2. gün ise sol tüp torakostomi sonlandirıldı. Postoperatif 6. günde taburcu edildi (Şekil5). Postoperatif kemoterapi alan hastanın 8 aydır devam eden takiplerinde herhangi bir patolojiye rastlanılmadı.

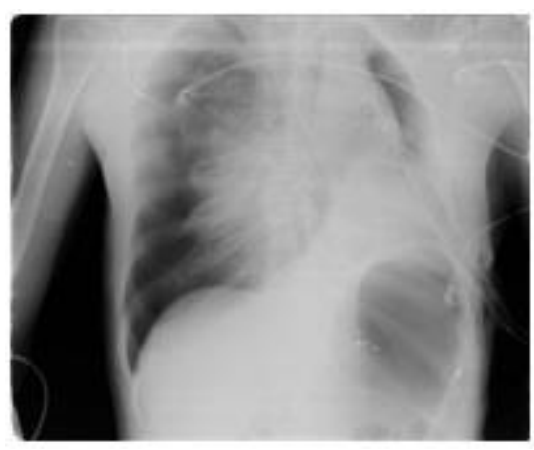

Şekil 4. Sol pnömonektomi sonrası erken dönem anterior posterior akciğer grafisinde sağ pnömotoraks görülmektedir

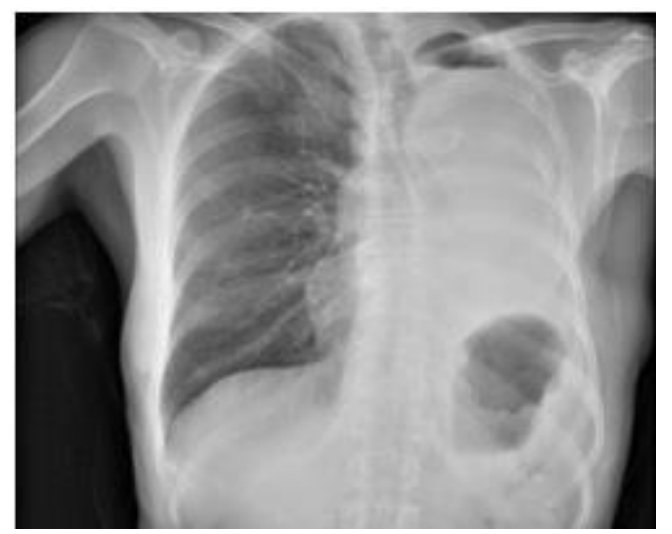

Şekil 5. Olgunun taburculuk posterior anterior akciğer grafisi

\section{TARTIŞMA}

Pnömotoraks, serbest hava birikiminin parietal ve visseral plevral yapraklar arasinda olmasıdır. Eski çağlardan beri bilinen pnömotoraks, ilk olarak 1724 yllında Boerhaave tarafindan tanımlamıştır. Ancak 1950 yllında tüp torakostomi rutin uygulamaya girmeye başlamıştır. Pnömotoraks; spontan, travmatik ve iyatrojenik olarak üç grupta değerlendirilebilir. Spontan pnömotoraks; primer veya sekonder olarak iki grupta incelenebilir. Travmatik pnömotoraks; künt gögüs travmaları veya kesici-delici alet yaralanmaları sonucu gelişir. Tanı veya tedavi amacıyla yapılan invazif işlemler sonucu ise iyatrojenik pnömotoraks oluşur. Sekonder pnömotoraks spontan veya travmaya bağlı görülse de, iyatrojenik pnömotorakslar tanı ve tedavi amaçlı invazif girişimlerin artmasına bağlı olarak daha sık karşılaşılmaktadır. Toraksa bağlı invazif işlemler olan transtorasik iğne biyopsileri, torasentez, transbronşiyal akciğer biyopsileri, bronkoskopi, trakeostomi, santral venöz kateter yerleştirilmesi, peruktan subklavyanven yoluyla yerleştirilen kalp pilleri, potansiyel olarak iyatrojenik pnömotoraks nedenleri arasındadır ${ }^{1}$. Sassoon ve arkadaşları 538 olguluk serilerinde, iyatrojenik pnömotorakslarda en çok rastlanılan sebebin transtorasik iğne aspirasyonu (\%23,7) olduğunu, bunu sirasiyla subklavyan uygulamalar $(\% 22,1)$, torasentez $(\% 19,7)$, transbronşiayal biyopsiler (\%10), plevra biyopsisi $(\% 8,3)$ ve mekanik ventilasyonun (\%7) takip ettiğini bildirmektedir². Olgumuzda santral kateter açılmamakla beraber torasentez sonrası pnömotoraks gelişmedi.

Pnömotoraks tedavisindeki amaç, plevral boşlukta biriken havayı boşaltmak ve tekrarlanmamasını sağlamaktır. Tedavi pnömotoraksın sınıfına, hava kaçağı ile pnömotoraksın primer veya sekonder olmasına göre düzenlenir ${ }^{3}$. Genellikle iyatrojenik pnömotoraksta tüp torakostomi uygulanır. Schoenenberger ve arkadaşları, iyatrojenik 
pnömotoraksların konvansiyonel kapalı su altı drenajı ile tedavi edilmesinin güvenilir ve efektif bir tedavi olduğunu bildirmişlerdir ${ }^{4}$.

Pnömonektomi sonrası en sık komplikasyonlar pulmoner ve kardiyak kökenlidir. En sık görülen komplikasyon ise aritmilerdir ${ }^{5}$. İleri yaşı bulunan akciğer dışı nedenler ile neoadjuvan tedavi almış bulunla birlikte ek hastalıkları bulunan hastaların akciğer rezeksiyonları sonrası görülen komplikasyon oranları ortalamadan anlamlı oranda yüksek seyreder ${ }^{6}$. Pnömonektomi sonrası kontralateral pnömotoraks gelişmesi nadir görülen bir durumdur ve ölümcül seyredebilir.

Olgumuzda hemoptizi ve nefes darlı̆̆ şikâyetlerinden dolayı çekilen CT'de aynı hemitoraksta kitle ve pnömotoraks olduğu saptanmıştır. Semptomlardan dolayı öncelikle kitleye yönelik operasyonlar planlandı. Postoperatif erken dönemde pnömotoraks oldukça ender bir durum olup; hava yolu basıncında artış, desatürasyon ve hipotansiyon ile bulgu verir.

Hastaya verilen lateral dekübit pozisyonu nedeniyle; oksültasyonun zorluğu tanı konulmasını zorlaştırabilir7?. Pnömonektomi olgularında acil pnömotoraks tanısı konulmazsa kardiyak arrest ile sonuçlanabilir. Hastamızda öncelikli olarak hava yolu basıncında artış ve desatürasyon gelişmesi üzerine tüp torakostomi uygulanmış, ardından solunumsal parametreler olağan seyretmiştir. Tedavisinde standart bir yöntem bulunmamakla birlikte, öncelikle drenaj sağlanması önerilmektedir. Ayrıca plörodez ya da operasyon kararı hastanın genel durumuna göre verilmektedir. Hastamızda çekilen tomografide sağ akciğerde bleb veya bül görülmemesi, bununla birlikte iyatrojenik pnömotoraks olarak değerlendirilmesi sebebiyle cerrahi düşünülmedi ve takip kararı alındl.

\section{SONUÇ}

Postoperatif pnömonektomi sonrası hastalarda solunumsal depresyonu desatürasyon ve kollaps durumunda masif kanama, kardiyak herniasyon, pnömotoraks ve mediastinal kayma ayırıcı tanıları hızlıca yapılmalıdır. Tüp torakostomi solunumsal parametreler düzelmesinde genellikle yeterli olmaktadır. Aynı hemitoraksta bulunan kitle ve pnömotoraks olgularında öncelikle semptomlar göz önüne alınmalıdır. Pnömonektomi olgularında gelişen pnömotoraks cerrahi endikasyon bulunmaktadır. Fakat olgumuzda da olduğu gibi pnömonektomi vakalarında iyatrojenik pnömotoraksa sadece tüp torakostomi uygulanmalıdır.

TÜSAD 38. Ulusal Kongresi, Solunum 2016, Çeşme-İzmir, 15-19.10.2016

Çıkar Çatışması Beyanı: Yazarlar çıkar çatışması olmadığını bildirmişlerdir.

Finansal Destek: Bu çalışma her hangi bir fon tarafından desteklenmemiştir.

Declaration of Conflicting Interests: The authors declare that they have no conflict of interest.

Financial Disclosure: No financial support was received.

\section{KAYNAKLAR}

1. Chen KY, Jerng JS, Liao WY, et al. Pneumothorax in the ICU: patient out comes and progno sticfactors. Chest. 2002;122:678-83.

2.Sassoon CS, Light RW, O'Hara VS, MoritzTE. Iatrogenic pneumothorax: etiology and morbidity. Results of a department of veterans affairs cooperative study. Respiration. 1992;59:215-20.

3. Yim APC, NgCSH. Thoracoscopy in the management of pneumothorax. Curr Opin Pulm Med. 2001;7:210-4.

4. Schoenenberger RA, Haefeli WE, Weis P. Evaluation of conventional chest tube therapyiatrogenic pneumothorax. Chest. 1993;104:1770-2. 
5. Myrdal G, Gustafsson G, Lambe M, Hörte LG, Ståhle E. Out come after lung cancer surgery. Factors predicting Early mortality and majör morbidity. Eur J Cardiothorac Surg, 2001;20:694-9.

6. Deslauriers J, Gregoire J, Jacques LF, Piraux M, Guojin L, Lacasse Y. Sleevelobectomy versus pneumonectomy for lung cancer: A comparative analysis of survival and sitesorrecurrences. Ann Thorac Surg, 2004;77:1152-6.
7. Finlayson GN, Chiang AB, Brodsky JB, Cannon WB. Intra operative contralateral tension pneumothorax during pneumonectomy. Anesth Analg;2008;106:58-60. 